\title{
Effect of preloading on haemodynamic of the patient undergoing surgery under spinal anaesthesia
}

\author{
Singh J'1, Ranjit $\mathbf{S}^{1}$, Shrestha $\mathrm{S}^{1}$, Sharma $\mathbf{R}^{2}$, Marahatta $\mathrm{SB}^{3}$ \\ ${ }^{1}$ Lecturer, Department of Anaesthesia, ${ }^{2}$ B.Sc Nursing Graduate, ${ }^{3}$ Assistant Professor, Department of Community \\ Medicine, Kathmandu University School of Medical Sciences, Dhulikhel Kavre, Nepal.
}

\begin{abstract}
Background: Hypotension and bradycardia after conduction of spinal anaesthesia are common side effects because of sympathetic blockade. Efforts to prevent these complications have been attempted like preloading with crystalloids, colloids or use of vasopressors. The role of volume preloading to prevent haemodynamic changes associated with spinal anaesthesia has been recently questioned.

Objective: The objective of the study was to investigate the effects of volume preload on changes of patient's hemodynamic.

Materials and methods: A Quasi- experimental design was used to conduct the study. Taking written informed consent, 40 patients of age group 18-45 years and ASA grade I and II undergoing surgery under spinal anaesthesia in operation theatre of Dhulikhel Hospital were selected as the sample of the study and allocated randomly to 2 groups. Group I did not receive volume preload and Group II received preload of $1000 \mathrm{ml}$ of Ringer's lactate solution within 30 minutes immediately before giving the spinal anaesthesia. An observational checklist was used to collect demographic, intraoperative and post-operative records of systolic blood pressure (SBP), diastolic blood pressure (DBP), mean arterial pressure (MAP) and heart rate (HR).

Results: The findings revealed that the haemodynamic changes occurred in all patients. The decrease in SBP, MBP and DBP from baseline was statistically significant at all points of time $(\mathrm{p}=0.000)$. The decrease in HR from baseline was not statistically significant at all points of time ( $>0.05)$. The overall incidence of hypotension was $50 \%$, among which $9(45 \%)$ were from without preload group and 11 (55\%) were from with preload group. The incidence of hypotension was similar in groups, sexes and surgical conditions (General Surgery, Gynae/Obs and Orthopaedics). There were no significant differences in haemodynamic changes among groups.
\end{abstract}

Conclusion: On the basis of findings, it is concluded that volume preloading had no effect on the incidence of hypotension and bradycardia after spinal anaesthesia.

Key words: Preload, Haemodynamics, Spinal Anaesthesia, Crystalloid

$\mathrm{H}$ ypotension and bradycardia after conduction of spinal anaesthesia are common side effects of spinal anaesthesia because of sympathetic blockade. Different techniques such as intravenous administration of fluid, wrapping of legs before surgery, and use of vasopressor before subarachnoid block etc have been used to prevent these complications. The practice of routinely prehydrating patients by infusion of intravenous solution for prevention of spinal anaesthesia induced hypotension and bradycardia has been challenged recently. Many studies have shown that the incidence and severity of hypotension and bradycardia are same whether preloaded or not ${ }^{1,2}$. The use of colloid solutions for spinal preloading met with mixed results. Gelatin solutions may be ineffective and have not achieved the degree of success seen with modified starch solutions $^{3,4}$.
Hypotension due to vasodilatation is usually maintained by reflex increase in cardiac output, but in spinal anaesthesia there is venodilation to an extent that the limited venous return cannot increase the cardiac output, rather decreases ${ }^{5}$. This study was conducted to evaluate the effect of volume preload before spinal anaesthesia on the haemodynamic changes of patient undergoing surgery under spinal anaesthesia.

Material and methods

The design of the present study was Quasi- experimental type. A total of 40 patients of the age group 18-45

\section{Correspondence}

Sujan B Marahatta

Department of Community Medicine Kathmandu University School of Medical Sciences, KUSMS Dhulikhel Kavre, Nepal

E-mail: sujanmarahatta@gmail.com 
years and of ASA grade I and II were recruited into the study. Among 40 patients, 20 were assigned randomly in the Experimental Group, receiving preload of 1000 $\mathrm{ml}$ Ringer's Lactate within 30 minutes before SA and 20 were assigned in the Control Group, receiving no preload. Patient with history of any other medical illness, sepsis, blood loss, cardiovascular disease, haemodynamically unstable patients, emergency cases, Caesarean Section and patients contraindicated to spinal anaesthesia were excluded from the study. The subjects were selected from surgery, gynaecology and orthopaedics department. The study subjects were selected in such a way that individual matching was done as per the type of the surgery carried out, with minimal blood loss, ASA I and ASAII and almost equal duration for surgery. Thus, group I and group II were matched as per the above factors during the selection of the study and surgery carried out on the same day without and with preloading respectively. The possible confounders, were well taken in control hence the bias has been minimized. The allotment in either group I or group II were by random allocation by using lottery method, each patient having equal chance to be included in either of the group.

Baseline haemodynamic parameters - SBP, DBP, MAP and HR were recorded just before performing spinal anaesthesia. Spinal anaesthesia was performed in the patient sitting position with $25 \mathrm{G}$ Quinke needle. $3 \mathrm{ml}$ of $0.5 \%$ heavy Bupivacaine was instilled in subarachnoid space between $3^{\text {rd }}$ and $4^{\text {th }}$ lumbar vertebra. Patients were immediately put on supine position and the above haemodynamic parameter was monitored every 5 minutes. They were compared at 1 minute, 5 minutes, 10 minutes, 20 minutes and 30 minutes.

Intraoperative intravenous fluid was maintained as per $4: 2: 1$ formula i.e. $4 \mathrm{ml} / \mathrm{kg} / \mathrm{hr}$ for $1^{\text {st }} 10 \mathrm{~kg}, 2 \mathrm{ml} / \mathrm{kg} / \mathrm{hr}$ for next $10 \mathrm{~kg}$ and then $1 \mathrm{ml} / \mathrm{kg} / \mathrm{hr}$ for rest of the body weight. Third space loss was calculated as $2 \mathrm{ml} / \mathrm{kg} / \mathrm{hr}$.

Any hypotension (Blood Pressure less than 25\% of the baseline) was treated with $500 \mathrm{ml}$ of Ringer lactate. Those unresponsive to fluid therapy were treated with titrated dose of intravenous Mephentermine. Any bradycardia (HR less than 50/minute) was treated with intravenous atropine $0.3 \mathrm{mg}$.

Data analyses were done under following subheadings:

- Age, gender, weight and height of the patient

- Baseline SBP, DBP, MAP and HR

- SBP, DBP, MAP and HR after performance of spinal anaesthesia

- Timeatwhichmaximumalterationinhaemodynamics occurred
- Total number of patients with hypotension and bradycardia in both the groups

Descriptive statistics such as frequency distribution and percentage were used to find out the demographic data; statistical analysis was done by using chi-square test and t-test to find out the association of SBP, DBP, MAP and HR with the haemodynamic changes after spinal anaesthesia.

\section{Results}

Out of 20 patients in without preload group, 9 (45\%) were male and $11(55 \%)$ were female. The mean age of all the patients was $35.5 \pm 9.66$ (Mean $\pm \mathrm{SD}$ ) year. The mean weight of all the patients was $53.89 \pm 8.02$ (Mean \pm SD) $\mathrm{kg}$. The mean height of all the patients was $1.55 \pm 0.09$ (Mean $\pm \mathrm{SD}$ ) meter. The mean BMI of all the patients was $22.39 \pm 2.99$ (Mean $\pm \mathrm{SD}$ ) $\mathrm{kg} / \mathrm{m}^{2}$.

There was no statistically significant difference between the groups in distribution of sex, age, height, BMI and baseline SBP $(p=0.14)$, DBP $(p=0.20), \operatorname{MBP}(p=0.17)$ and HR $(\mathrm{p}=0.39)$.

In the control group SBP decreased following induction of SA from a baseline value of $127.9 \pm 11.72 \mathrm{mmHg}$ to $107.75 \pm 11.44 \mathrm{mmHg}$ by the end of 30 minutes. The decrease in SBP from baseline was statistically significant at all points of time $(\mathrm{p}=0.000)$.

In Study Group SBP decreased following induction of SA from a baseline value of $137.05 \pm 24.59 \mathrm{mmHg}$ to $117.7 \pm 19.13 \mathrm{mmHg}$ by the end of 30 minutes. The decrease in SBP from baseline was statistically significant at all points of time $(\mathrm{p}=0.000)$.

With further analyze SBP changes during 30 minutes, it showed that the maximum decrease occurred in $30^{\text {th }}$ min after SA There was no statistically significant difference in the SBP at $1^{\text {st }}, 5^{\text {th }}, 10^{\text {th }}, 20^{\text {th }}$ and $30^{\text {th }} \mathrm{min}$ after induction of SA. The decrease in SBP was more amongst without preload groups $(107.75 \pm 11.44)$ at $30^{\text {th }}$ min than preload group $(113 \pm 28.05)$ at $5^{\text {th }}$ min after induction of SA (Fig 3).

In Control Group DBP decreased following induction of SA from a baseline value of $78.55 \pm 9.53 \mathrm{mmHg}$ to $63.1 \pm 8.21 \mathrm{mmHg}$ by the end of 30 minutes. The decrease in DBP from baseline was statistically significant at all points of time $(\mathrm{p}=0.000)$. Maximum decrease occurred in $30^{\text {th }} \mathrm{min}$ after $\mathrm{SA}$ i.e. $63.1 \pm 8.21$.

In Study Group DBP decreased following induction of SA from a baseline value of $83.3 \pm 13.51 \mathrm{mmHg}$ to $70 \pm 14.10 \mathrm{mmHg}$ by the end of 30 minutes. The decrease in DBP from baseline was statistically significant at all 
points of time ( $\mathrm{p}=0.000)$. Maximum decrease occurred in $5^{\text {th }}$ min after SA i.e. $67.75 \pm 16.36 \mathrm{mmHg}$.

DBP decreased in both the groups after induction of SA from baseline values. There was no statistically significant difference in the DBP at $1^{\text {st }}, 5^{\text {th }}, 10^{\text {th }}, 20^{\text {th }}$ and $30^{\text {th }}$ min after induction of SA. The decrease in DBP was high amongst without preload group $63.1 \pm 8.21 \mathrm{mmHg}$ at $30^{\text {th }}$ min than preload group $67.75 \pm 16.36 \mathrm{mmHg}$ at $5^{\text {th }}$ min after induction of SA (Fig 4).

In Control Group MBP decreased following induction of SA from a baseline value of $98.5 \pm 14.05 \mathrm{mmHg}$ to $81.3 \pm 10.53 \mathrm{mmHg}$ by the end of 30 minutes. The decrease in MBP from baseline was statistically significant at all points of time $(\mathrm{p}=0.000)$.maximum decrease occurred in $30^{\text {th }}$ min after SA i.e. $81.3 \pm 10.53$ $\mathrm{mmHg}$.

In Study Group MBP decreased following induction of SA from a baseline value of $106.1 \pm 19.90 \mathrm{mmHg}$ to $87.1 \pm 15.49 \mathrm{mmHg}$ by the end of 30 minutes. The decrease in MBP from baseline was statistically significant at all points of time $(\mathrm{p}=0.000)$.maximum decrease occurred in $5^{\text {th }}$ minute after SA i.e. $85.55 \pm 21.37$ $\mathrm{mmHg}$. At $30^{\text {th }}$ minute it was $87.1 \pm 15.49 \mathrm{mmHg}$.

MBP decreased in both the groups after induction of SA from baseline values. There was no statistically significant difference in the MBP at $1^{\text {st }}, 5^{\text {th }}, 10^{\text {th }}, 20^{\text {th }}$ and $30^{\text {th }} \mathrm{min}$ after induction of $\mathrm{SA}$. The maximum decrease in MBP was more amongst without preload groups $(81.3 \pm 10.53)$ at $30^{\text {th }}$ min than preload group $(85.55 \pm 21.37)$ at $5^{\text {th }}$ min after induction of SA (Fig 5).
In Control Group HR decreased following induction of SA from a baseline value of $74.95 \pm 12.71 \mathrm{mmHg}$ to $70.6 \pm 13.69 \mathrm{mmHg}$ and increased to $76.05 \pm 15.49$ $\mathrm{mmHg}$ by the end of 30 minutes. The decrease in HR from baseline was not statistically significant at all points of time ( $p>0.05)$.maximum decrease occurred in $20^{\text {th }}$ min after SA i.e. $70.6 \pm 13.69$.

In Study Group HR decreased following induction of SA from a baseline value of $78.25 \pm 11.68$ to $70.5 \pm 11.75$ by the end of 30 minutes. The decrease in HR from baseline was not statistically significant at all points of time $(\mathrm{p}>0.05)$.

With further analysis of HR changes during 30 minutes, it showed that the maximum decrease occurred in $30^{\text {th }}$ min after SA i.e. $70.5 \pm 11.75 \mathrm{mmHg}$.

HR decreased in both the groups after induction of SA from baseline values. There was no statistically significant difference in the HR at $1^{\text {st }}, 5^{\text {th }}, 10^{\text {th }}, 20^{\text {th }}$ and $30^{\text {th }}$ min after induction of SA. The decrease in HR was not significantly different in both group, in Control Group $=70.6 \pm 13.69$ at $20^{\text {th }}$ min and Study Group $=$ $70.5 \pm 11.75$ at $30^{\text {th }} \min$ (Fig 6) ( $\left.>0.05\right)$.

Among 40 patients, 20 patients developed hypotension in which $9(45 \%)$ were from Control Group and 11 (55\%) were from Study Group.

Total $8(20 \%)$ patients required rescue fluid, among which 3 (7.5\%) were from Control Group and 5 (12.5\%) were from Study Group. Only 1 patient $(2.5 \%)$ required atropine that was from Study Group and the amount was $0.6 \mathrm{mg}$ of atropine.

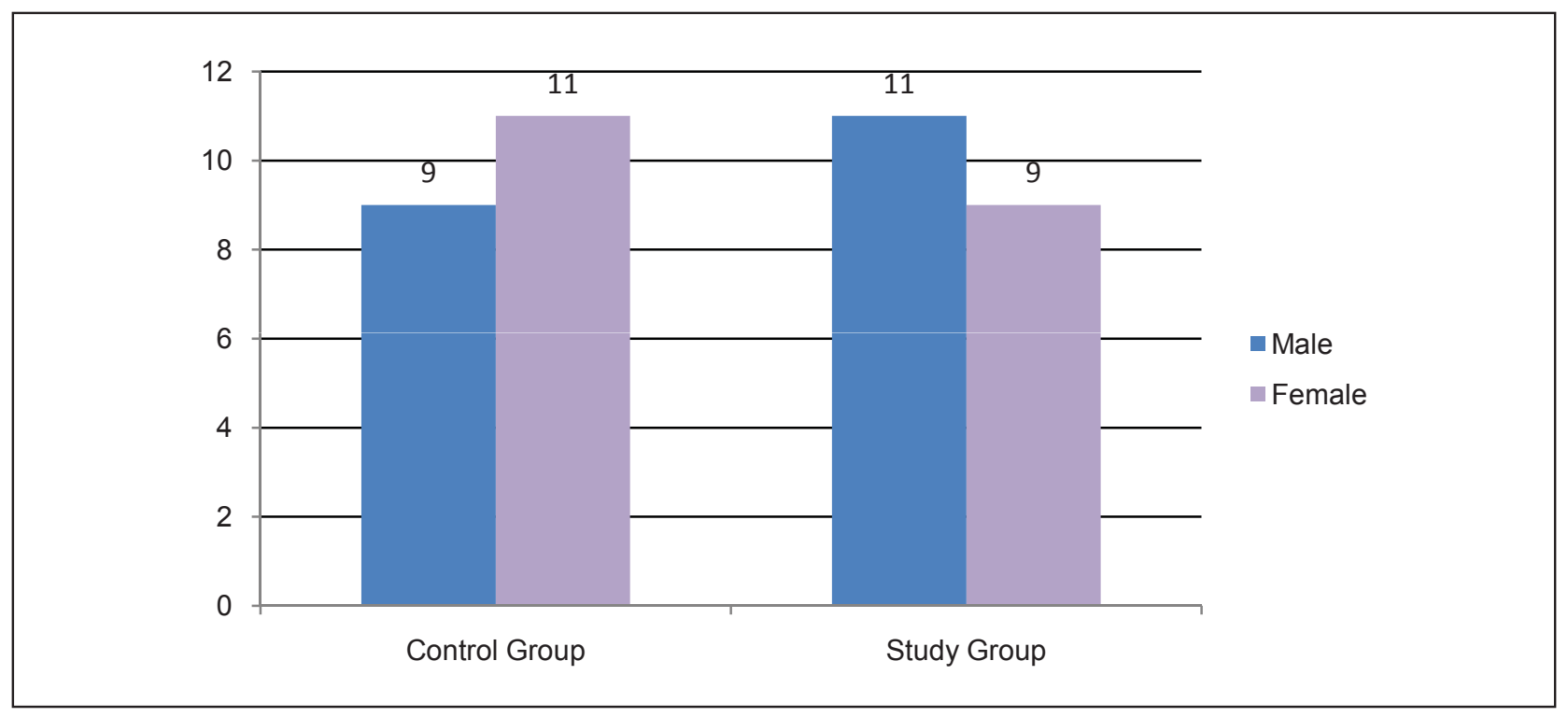

Fig 1: Sex distribution 


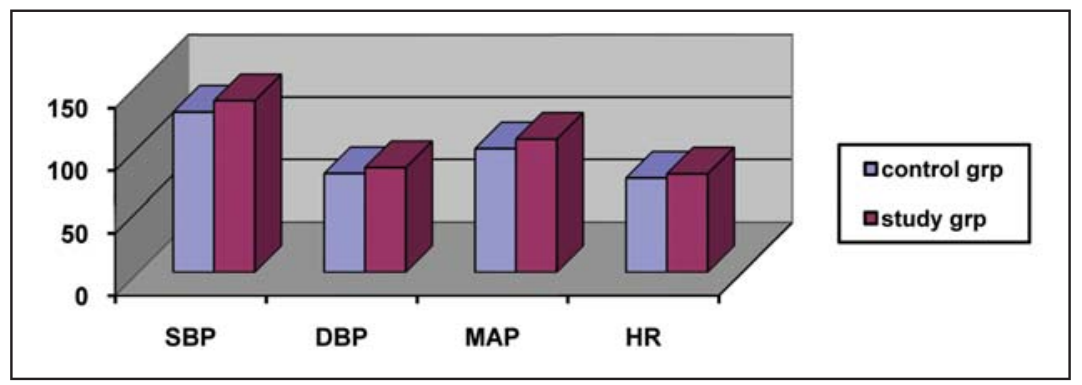

Fig 2: Baseline values of the two groups

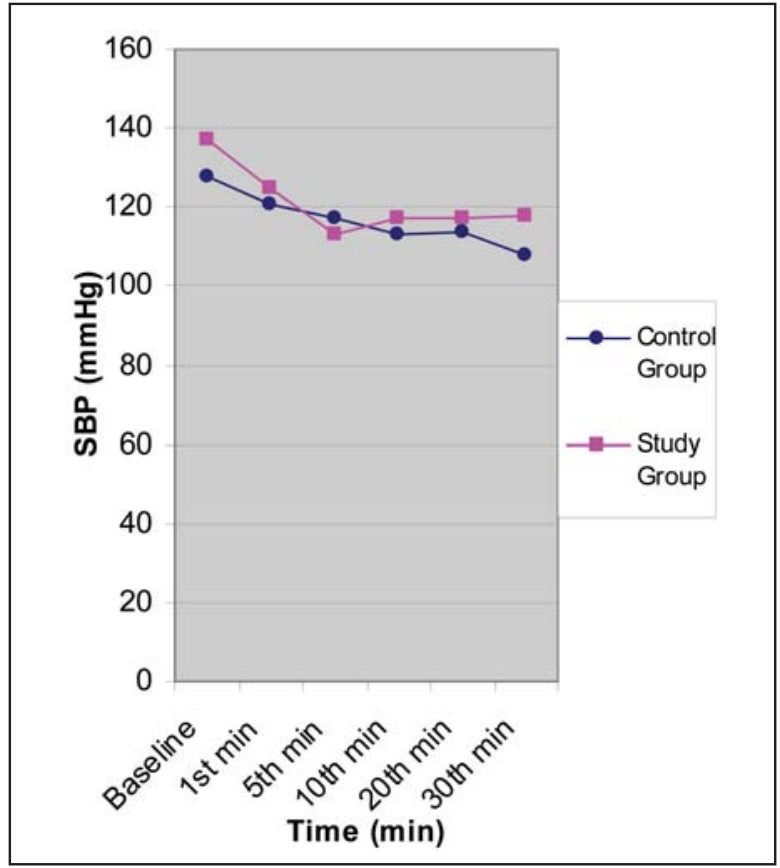

Fig 3: Showing SBP changes after induction of SA in control and study group

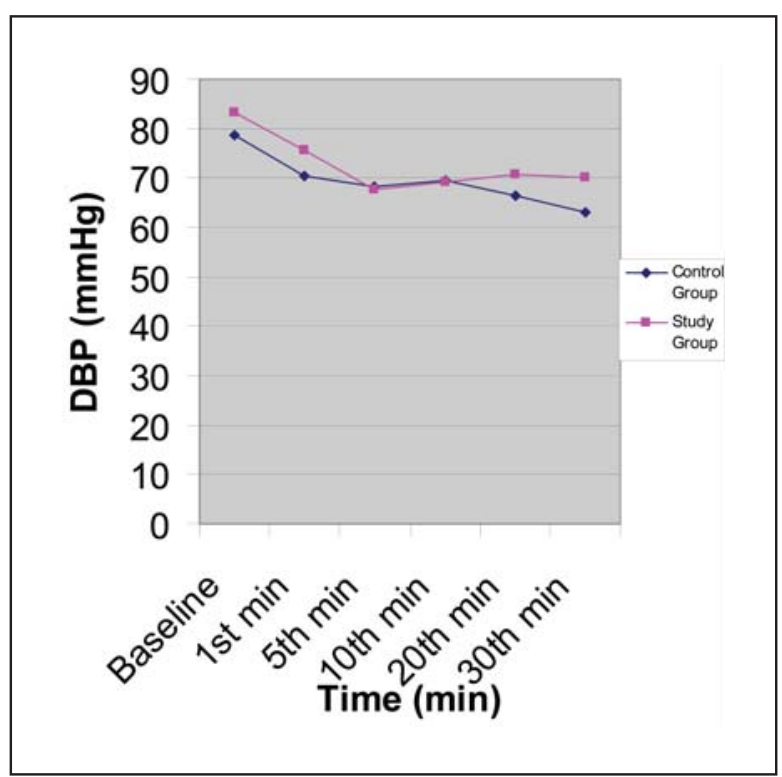

Fig 4: Showing DBP changes after induction of SA in control and study group

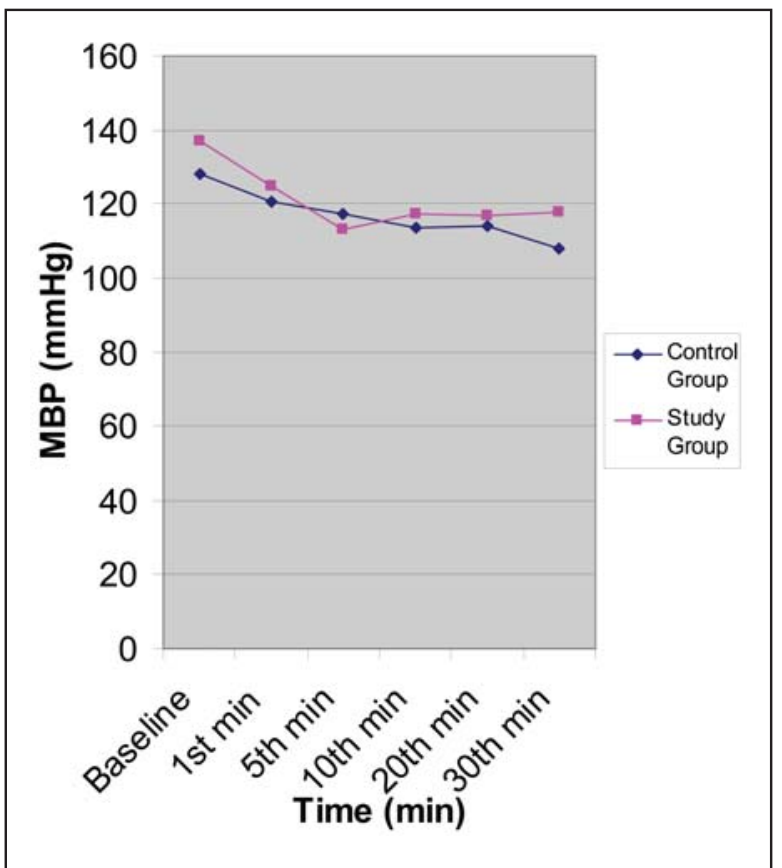

Fig 5: Showing MBP changes after induction of SA in control and study group

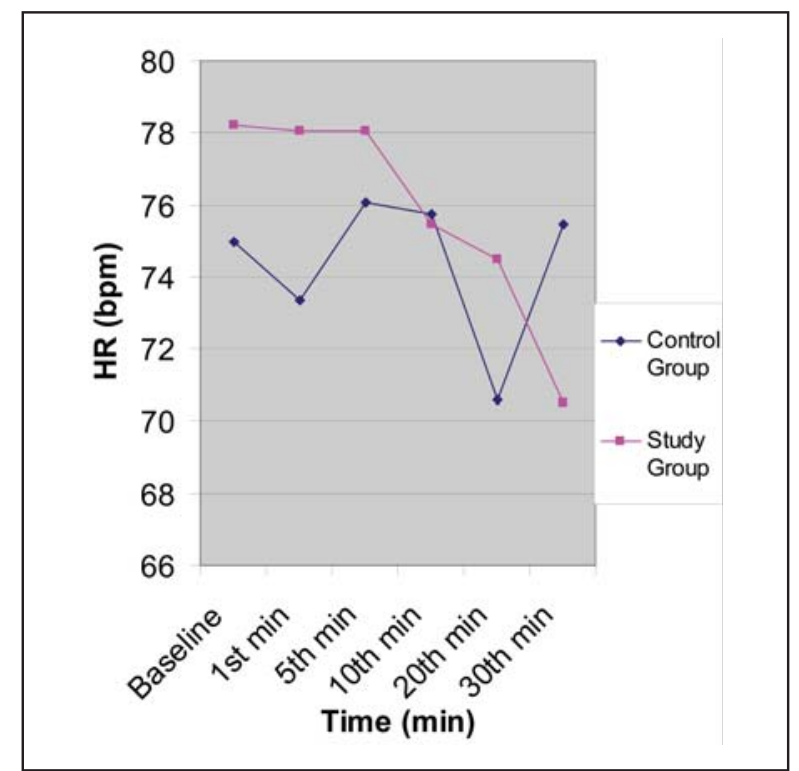

Fig 6: Showing HR changes after induction of SA in control and study group 


\section{Discussion}

Different techniques such as intravenous administration of fluid and different vasopressors have been used to prevent Hypotension and bradycardia after performing spinal anaesthesia. The goal of administrating fluid before spinal block is to increase venous return and preserve central blood volume and cardiac output, both of which decrease after spinal anaesthesia as a consequence of sympathetic blockade.

The present study was conducted to evaluate the effect of volume preload before spinal anaesthesia on the haemodynamic changes of patient undergoing surgery under spinal anaesthesia.

This study showed that there were haemodynamic changes in all patients undergoing surgery under spinal anaesthesia. Haemodynamic variables (SBP, DBP, MBP and HR) decreased in all patients after induction of spinal anaesthesia by the end of 30 minutes. Among 40 patients, $20(50 \%)$ had hypotension and among them $9(22.5 \%)$ needed rescue drug, $8(20 \%)$ patients needed rescue fluid for the management of hypotension. Similarly $13(32.5 \%)$ patients had bradycardia among which $1(2.5 \%)$ patient needed atropine and 5 (12.5\%) patients had tachycardia.

These findings were consistent with the finding of Das ${ }^{6}$ which revealed that 7 patients out of 20 patients had a significant fall in heart rate during intraoperative period which was managed by IV injection, Atropine $0.6 \mathrm{mg}$. Similarly 20 patients of spinal group had fall in BP intraoperatively which was managed either by IV fluid or vasopressors. Similarly a study of Kyokong et $\mathrm{al}^{7}$ revealed that incidence of hypotension and bradycardia was $36.8 \%$ and $4.9 \%$ respectively. Arndt et a ${ }^{8}$ concluded that the cardiovascular effects may occur at any time during spinal anaesthesia.

In this study we compared the haemodynamic changes between the two groups: receiving and not receiving preload. The findings revealed that the association of group with hypotension and heart rate changes was not statistically significant. The finding was consistent with the result of study done by Yokoyama et $\mathrm{al}^{9}$ that volume preloading has little effect on maternal haemodynamics and neonatal outcomes suggesting that stable perioperative management is possible with or without volume preload before spinal anaesthesia. Similarly Jackson et $\mathrm{al}^{10}$ concluded that volume preloading is not essential to prevent spinal induced hypotension. They found no difference between 2 groups receiving and not receiving fluid and abandoned the routine of preloading before spinal anaesthesia.
But the results of this study were not consistent with several studies done previously. Cyna et $\mathrm{al}^{11}$ concluded that crystalloid were more effective than no fluids with relative risk of 0.78 in preventing hypotension following spinal anaesthesia.

This study also studied the association of sex and surgical conditions (General Surgery, Gynae/Obs and Orthopaedics) with incidence of hypotension and bradycardia after spinal anaesthesia. It concluded that there was no significant association between sex and surgical conditions with haemodynamic changes after spinal anaesthesia $(p>0.05)$. But this result was not consistent with the study done by Bernt Hartmann ${ }^{12}$ who identified surgical conditions (General Surgery, Gynae/ Obs and Orthopaedics) as the variable associated with hypotension after spinal anaesthesia.

In summary, this study showed that administering crystalloids before spinal anaesthesia had no beneficial effect in preventing cardiovascular side effects in surgeries of patient undergoing spinal anaesthesia as compared with administering without preloading fluid before spinal anaesthesia.

\section{Conclusion}

This prospective study was done at Dhulikhel Hospital, KUTH, Dhulikhel, and Kavre to evaluate the haemodynamic changes in 40 patients undergoing surgery under spinal anaesthesia. There were haemodynamic changes in all patients undergoing surgery under spinal anaesthesia at all points of time after induction of spinal anaesthesia. SBP, DBP, MBP and HR decreased following induction of spinal anaesthesia by the end of 30 minutes. The decrease from baseline was statistically significant at all points of time. Maximum decrease occurred in $30^{\text {th }}$ min after spinal anaesthesia.

Statistically, there was no significant difference in the incidence of hypotension and heart rate changes among groups (Control Group and Study Group), sex (Male and Female) and surgical conditions (General Surgery, Gynae/Obs and Orthopaedics) as the incidence of hypotension and heart rate changes were similar in the groups, sexes and surgical departments.

It is concluded that the preloading with crystalloid before giving spinal anaesthesia is not effective in preventing the incidence of haemodynamic change. Hence the practice of routinely infusing crystalloid before induction spinal anaesthesia is not essential. 


\section{References}

1. Jackson Reid JA, Thorburn J. Volume preloading is not essential to prevent spinalinduced hypotension at caesarean section. BJA.1995;75:262-5.

2. Critchley LAH. Hypotension, subarachnoid block and the elderly patient. Anaesthesia. 1996;51:1139-43.

3. Vercauteren HP, Hoffman V, Coppejans HC. Hydroxyethyl starch compared with modified gelatin as volume preload before spinal anaesthesia for caesarean section. BJA. 1996;76:731-3.

4. Riley ET, Cohen SE, Rubenstein AJ, Flanagan B. Prevention of hypotension after spinal anaesthesia for cesarean section: Six percent Hetastarch versus lactated Ringer's solution. Anaesthesia Analog. 1995;81:838-42.

5. Green NM, Brull SJ. The cardiovascular system, Physiology of spinal anaesthesia. Baltimore: William and Wilkins;1993.p. 85-199.

6. Das, S. Combined spinal epidural block versus epidural block and spinal block for elective surgery. Kathmandu: Kathmandu University; 2006.

7. Kyokong O, Charuluxananan S, Sriprajittichai $\mathrm{P}$, Poomseetong $\mathrm{T}$ and Naksin P. The incidence and risk factors of hypotension and bradycardia associated with spinal anesthesia. J Med Assoc Thai. 2006; 89(3):58-64.
8. Arndt, JO, Bomer, W, Krauth, J and Marquardt, B Incidence and time course of cardiovascular side effects during spinal anaesthesia after prophylactic administration of intravenous fluids or vasoconstrictors. Anaesthesia Analog. 1998; 87(2):347-54.

9. Yokoyama N, Nishikawa, K Saito, Y, Saito, $\mathrm{S}$ and Goto F. Comparison of the effects of colloid and crystalloid solution for volume preloading on maternal hemodynamics and neonatal outcomes in spinal anaesthesia for cesarean section. The Jpn J Anesthesiol. 2004; 53(9):1019-24.

10. Jackson, R, Reid, JA and Thorburn, J. Volume preloading is not essential to prevent spinal induced hypotension at cesarean section. BJA. 1995;75(3):262-5.

11. Cyna, A.M., Andrew, M., Emmett, R.S., Middleton, P. and Simmons, S.W. Techniques for preventing hypotension during spinal anaesthesia for cesarean section. Cochrane Database Systematic Review. 2006;18(4): CD002251.

12. Hartmann, B, Junger, A, Klasen, J, Benson, M, Jost A, Banzhaf A and Hempelmann, G. The incidence and risk factors for hypotension after spinal anaesthesia induction: an analysis with automated data collection. Anaesthesia Analog. 2002;94:1521-9. 